\title{
Induction of in vitro flowering in Capsicum frutescens under the influence of silver nitrate and cobalt chloride and pollen transformation
}

\author{
Ashwani Sharma \\ Plant Cell Biotechnology Department \\ Central Food Technological Research Institute \\ Mysore - 570 020, Karnataka State, India \\ Tel: 9108212516501 \\ Fax: 9108212517233 \\ E-mail: pcbt@cftri.res.in
}

\section{Vinod Kumar}

Plant Cell Biotechnology Department

Central Food Technological Research Institute

Mysore - 570 020, Karnataka State, India

Tel: 9108212516501

Fax: 9108212517233

E-mail:pcbt@cftri.res.in

\section{Parvatam Giridhar}

Plant Cell Biotechnology Department

Central Food Technological Research Institute

Mysore - 570 020, Karnataka State, India

Tel: 9108212516501

Fax: 9108212517233

E-mail: pcbt@cftri.res.in

Financial support: This study is covered under Indian patent (Del No. \#764/Del/2004).

Keywords: Capsicum frutescens, cobalt chloride, in vitro flowering, pollen transformation, regeneration, silver nitrate.

Abbreviations: ANOVA: Analysis of Variance

LB: Luria Bertani

MS: Murashige and Skoog

The influence of silver nitrate $\left(\mathrm{AgNO}_{3}\right)$ and cobalt chloride $\left(\mathrm{CoCl}_{2}\right)$ on shoot multiplication and in vitro flowering in Capsicum frutescens Mill. was investigated. Exogenous administration of $\mathrm{AgNO}_{3}$ and $\mathrm{CoCl}_{2}$ at a concentration of $30 \mu \mathrm{M}$ resulted in the maximum tissue response in terms of shoot length and number of shoots after 45 days culturing on MS medium. Both silver nitrate $(40 \mu \mathrm{M})$ and cobalt chloride $(30 \mu \mathrm{M})$ influenced in vitro flowering after 25 and 45 days respectively. This is the first report on in vitro flowering in $C$. frutescens. The study also demonstrated successful transformation of pollen obtained from the in vitro flowers. Since capsicum is highly recalcitrant to in vitro plant regeneration, the results of the study may be highly useful in transformation of capsicum using germ free in vitro flowers.
Capsicum frutescens Mill. is an important horticultural crop belonging to the Solanaceae. This genus includes many species of which major ones are Capsicum frutescens Mill. and Capsicum annuum L. Chili peppers are cultivated for vegetables as well as condiments and also used around the world as sweet peppers, pungent chili peppers; or as a source of dried powders of various colors (Ravishankar et al. 2003). Mild and high pungent varieties of peppers are used for the fresh market and for processing while those of the low pungent varieties are used for production of oleoresin and additives. Even though other Solanaceae members easily undergo morphogenesis, chili was found to be highly recalcitrant (Ochoa-Alejo and Ramirez-Malagon, 2001). Application of cell and molecular biology techniques for genetic improvement has been limited

*Corresponding author 
because of the difficulties in plant regeneration (OchoaAlejo and Ramirez-Malagon, 2001). Conventional breeding methods can only use those genes that are present in species that are sexually compatible with $C$. frutescens. Recombinant DNA manipulation of Capsicum species has been unsuccessful because of the difficulty in regenerating whole plants by tissue culture, in general, and through callus, in particular. For these reasons, it would be desirable to provide improved methods for the regeneration of whole plant by in vitro multiplication.

The morphogenetic potential of C. annuum using hypocotyl, leaf explants or cotyledon explants (ValeraMontero and Ochoa-Alejo, 1992) has been reported earlier; however the responses were genotype specific (Hyde and Phillips, 1996) and also produced low frequencies of shoot regeneration. Only sporadic reports on regeneration are available for the short-lived perennial, highly pungent bird's eye chili, C. frutescens. Recently Gururaj et al. (2004) attempted in vitro clonal propagation in $C$. frutescens, wherein a maximum of 1-3 shoots were reported. A highly reproducible regeneration system with greater frequency of multiple shoot production is required to improve this important crop through genetic engineering especially in order to mobilize the desired pungency gene (Prasad et al. 2006) for its over expression or suppression for better economic perspective. Silver ions are reported to inhibit ethylene action (Beyer, 1976) whereas cobalt ions inhibit ethylene biosynthesis (Roustan et al. 1989). The morphogenetic potential of these two compounds were well documented in different plant systems such as Coffea (Giridhar et al. 2003; Giridhar et al. 2004), Decalepis (Obul Reddy et al. 2001), Vanilla (Giridhar et al. 2001). Even though Agrobacterium mediated genetic transformation of

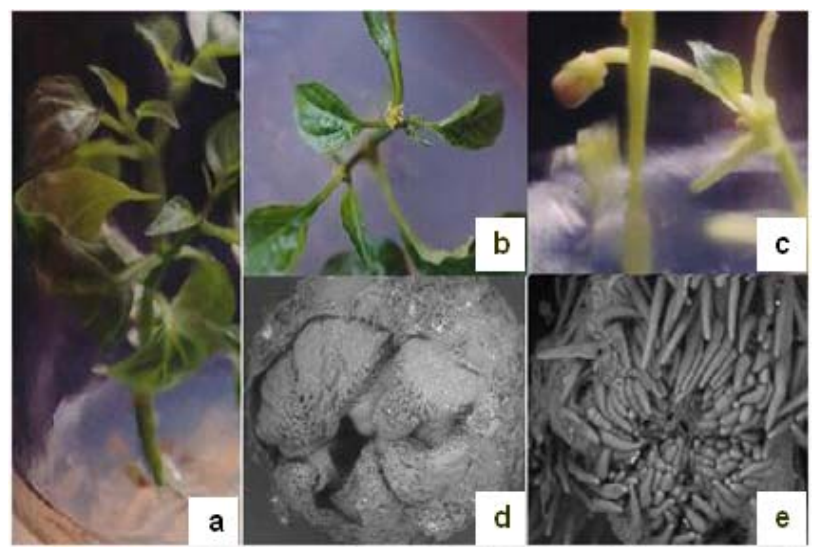

Figure 1a. In vitro shoot growth of Capsicum frutescens using silver nitrate at $30 \mu \mathrm{M}$ on MS basal medium.

Figure 1b. Induction of in vitro flower bud under the influence of the $50 \mu \mathrm{M}$ cobalt chloride on MS basal medium.

Figure 1c. Induction of in vitro flower bud under the influence of $40 \mu \mathrm{M}$ silver nitrate on MS basal medium.

Figure 1d. SEM photograph of in vitro flower bud at $40 \mu \mathrm{M}$ of silver nitrate.

Figure 1e. SEM photograph of in vitro flower bud at $50 \mu \mathrm{M}$ cobalt chloride.
C. annuum has been reported earlier, due to lack of efficient regeneration methods the same can not be used effectively for biotechnological improvement of this important crop. Apart from this there are no reports in pollen transformation in Capsicum sp. Flowering is considered as a complex process regulated by environment and physiological factors and its occurrence in in vitro culture is relatively rare. In vitro floral induction has been reported for several plant species to name a few chicory (Bais et al. 2000), cowpea (Brar et al. 1999), ginseng (Tang, 2000), and also in C. annuum; but such reports are lacking in high pungent $C$. frutescens. Flowering from plantlet may provide a ready to use source of sterile ovaries and microspores for gametophytic transformation. In this communication we are reporting the influence of ethylene synthesis and ethylene action inhibitors on in vitro flowering and plant morphogenesis in C. frutescens. We have also put forth the pollen transformation; for which microspore stage of pollen, 48 before the anthesis from the unopened flower of C. frutescens Var. KT-OC was used for the study and the same microspores were kept for the co-cultivation for 12 hrs.

\section{MATERIALS AND METHODS}

\section{Plant material}

Seeds from Capsicum frutescens Mill. 'KTOC' were obtained from The Defence Research Development Organization (DRDO), Pithoragarh, Uttaranchal, India. As we have collected the seeds from DRDO Uttranchal, we don't have that specific information about seed lot no. etc, which may be available with DRDO. We have tested the \% seed germination and it was $90 \%$. As this was not necessary for the experiment the same was not provided in the material and methods section. As it is from the authenticated organization (DRDO) and they have not revealed the source plant, accessions etc.

\section{Preparation of explant}

The decontamination of seeds was performed by first rinsing the seeds in $70 \%$ ethanol for $10 \mathrm{sec}$ followed by surface sterilization in an aqueous solution of $0.1 \%(\mathrm{w} / \mathrm{v})$ $\mathrm{HgCl}_{2}$ for 3-5 min followed by 3-4 times rinsing with sterile distilled water. Seeds were cultivated onto Murashige and Skoog (MS) medium (Murashige and Skoog, 1962) supplemented with 3\% sucrose (Himedia Mumbai, India) and gelled with $0.8 \%$ Agar and no PGRs. For the seed germination no Plant growth regulators were used, it was plain MS media.

\section{In vitro shoots multiplication}

Fifteen days old nodal explants were aseptically inoculated on modified MS basal medium supplemented with silver nitrate $\left(\mathrm{AgNO}_{3}\right)$ and cobalt chloride $\left(\mathrm{CoCl}_{2}\right)$ with concentrations ranging from 0 to $50 \mu \mathrm{M}$ (Table 1 and Table 2). 
The $\mathrm{pH}$ of the media was adjusted to $5.8 \pm 0.2$ before gelling with $0.8 \%$ agar (Himedia Mumbai, India). The gelled media was autoclaved at $1.06 \mathrm{~kg} \mathrm{~cm}^{-2}$ pressure and $121^{\circ} \mathrm{C}$ for $15 \mathrm{~min}$. The cultures were incubated at $25 \pm 2^{\circ} \mathrm{C}$ and at $16 \mathrm{hrs}$ in light under cool light $\left(4.41 \mathrm{Jm}^{-2} \mathrm{~s}^{-1}\right)$ using fluorescent lights. Data for shoot length Shoot length was from the intact shoots in flask using scale and an average of 6 shoots are given in the tables, and in vitro flowering of terminal shoots were recorded on $15^{\text {th }}, 25^{\text {th }}$ and $45^{\text {th }}$ day after inoculation.

\section{Pollen transformation}

Anthers were dissected from the in vitro flowers and pricked with a sterile needle soaked in Agrobacterium tumefaciens strain EHA 101 inoculum. A. tumefaciens EHA 101 containing the binary vector pCAMBIA 1301 harboring selectable marker gene hygromycin phosphotransferase (hpt II) under the control of the CaMV $35 \mathrm{~S}$ promoter and CaMV $35 \mathrm{~S}$ terminator; $\beta$-glucuronidase (uid $\mathrm{A}$ ) gene under the control of CaMV $35 \mathrm{~S}$ promoter and NOS terminator. A. tumefaciens harbouring the binary vector was maintained in Luria Bertani (LB) medium with $50 \mathrm{mg} \mathrm{l}^{-1}$ kanamycin solidified with $1.5 \%$ Agar. Cultures were grown overnight in LB medium, supplemented with $50 \mathrm{mg}^{-1}$ kanamycin at $28^{\circ} \mathrm{C}$ and at $120 \mathrm{rpm}\left(\mathrm{OD}_{600}: 0.5-\right.$ 1.00 ), prior to transformation. The cells were harvested by centrifugation at $4,000 \mathrm{rpm}$ for $5 \mathrm{~min}$, resuspended in infection medium comprising half strength MS salts with $1.0 \mathrm{mg} \mathrm{l}^{-1}$, niacin, $1.0 \mathrm{mg} \mathrm{l}^{-1}$, pyridoxine $\mathrm{HCl}, 10 \mathrm{mg} \mathrm{l}^{-1}$, thiamine $\mathrm{HCl}, 2 \%$ sucrose and $200 \mu \mathrm{M}$ acetosyringone (Sigma, USA) and used for co-cultivation. The anthers were co-cultivated for $6 \mathrm{hrs}$ and $12 \mathrm{hrs}$ duration in independent experiments.

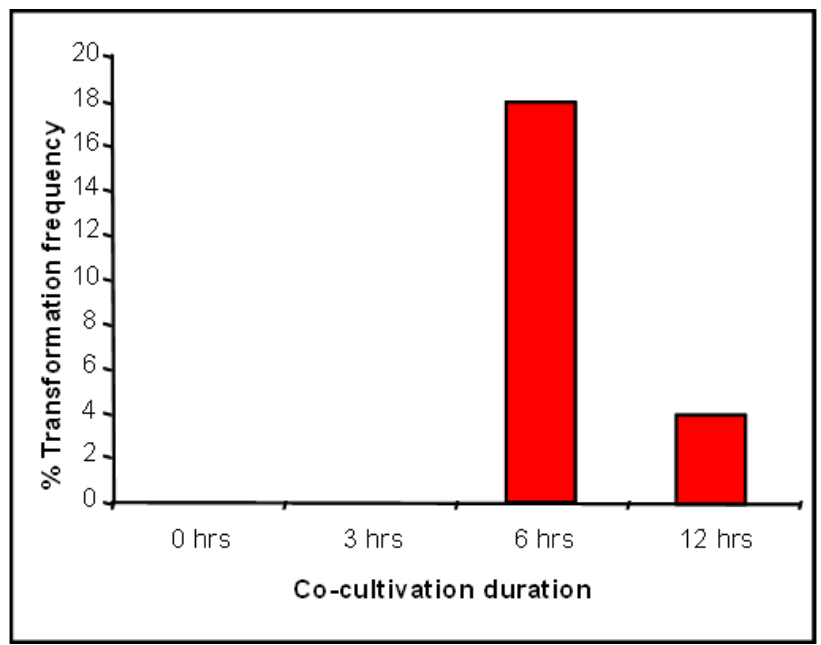

Figure 2. Percentage transformation frequency of Capsicum frutescens pollen co-cultivated with Agrobacterium tumefaciens. Maximum transformation frequency was observed in $06 \mathrm{hrs}$ co-cultivation treatment.

\section{GUS assay}

GUS assay was performed by immersing the anthers for 12 hrs at $37^{\circ} \mathrm{C}$ in a GUS assay buffer containing $100 \mathrm{mM}$ sodium phosphate ( $\mathrm{pH} 7$ ), $20 \mathrm{mM}$ EDTA, $0.1 \%$ triton X$100,1 \mathrm{mM}$ potassium ferrocyanide, $1 \mathrm{mM}$ potassium ferricyanide, $20 \%$ methanol, and $1 \mathrm{mM} \mathrm{X-Gluc} \mathrm{(5-bromo}$ 4-chloro indolyl-D-glucuronide cyclo-hexamonium salt) from Sigma, USA. Methanol was added to the reaction mixture to suppress endogenous GUS like activity. The results were expressed in terms of percentage pollen transformation frequency.

$\%$ Pollen transformation frequency $=\frac{\text { Number of pollen grains with blue GUS staining } \times 100}{\text { Total number of pollen grains in microscopic field }}$

The experiment was conducted with CRD design and results were analyzed using Analysis of Variance (ANOVA) and significant test by Tukey's Honesty Significant Difference (HSD at $=0.05$ ) procedure for mean separation. All the treatments had 10 replicates and experiments were repeated three times.

\section{RESULTS}

\section{In vitro growth of shoots and in vitro flowering}

Seed germination on MS basal medium was $90 \%$ and it took 26-32 days to grow up to single node. Nodal explants inoculated on MS medium with $30 \mu \mathrm{M}$ of silver nitrate responded well for shoot growth wherein 2.5 fold increase after 45 days was obtained (Table 1 and Figure 1a) compared to the control. Similarly $30 \mu \mathrm{M}$ of cobalt chloride supplemented media also influenced shoot growth up to 2.2 fold after 45 days compared to the control (Table 2 and Figure 1b). Silver nitrate when used at lower concentration $(10 \mu \mathrm{M})$ did not induce flowering during 25 day of culture, even by 45 days only single flower was noticed (Table 1 ) but the flower induction was more at $20-50 \mu \mathrm{M}$ of $\mathrm{AgNO}_{3}$ with $40 \mu \mathrm{M}$ as optimum concentration wherein, a maximum of 7 flowers were noticed on single plant, even by 25 days 4 flowers were induced at the same concentration. But, the optimum concentration of $\mathrm{AgNO}_{3}$ was $30 \mu \mathrm{M}$ for obtaining maximum shoot length $(6.4 \pm 0.4$ $\mathrm{cm})$ after 45 day of culture Significance between the treatment have been found using one-way ANOVA and the means of the different treatments were separated using DMRT and student t-test etc.

Similarly lower concentration of $\mathrm{CoCl}_{2}(10 \mu \mathrm{M})$ did not showed any flower induction during the first 25 days of culture, but able to induce only single flower after 45 days of culturing. The flower induction was more at 20-50 $\mu \mathrm{M}$ of $\mathrm{CoCl}_{2}$ with $30 \mu \mathrm{M}$ as optimum concentration wherein a maximum of 7 flowers were observed on single in vitro plant (Table 2). Even the shoot length was more at $30 \mu \mathrm{M}$ $\mathrm{CoCl}_{2}(5.4 \pm 0.4 \mathrm{~cm})$.

After 45 days, culture with silver nitrate $(40 \mu \mathrm{M})$ (Figure 1c, and Figure 1d) and with $30 \mu \mathrm{M}$ cobalt chloride (Figure 
Table 1. Effect of silver nitrate concentrations on shoot length and in vitro flowering (no. of flowers) in Capsicum frutescens.

\begin{tabular}{|c|c|c|c|c|c|c|}
\hline \multirow{2}{*}{ S. no. } & \multirow{2}{*}{$\begin{array}{c}\text { Conc. of silver } \\
\text { nitrate }(\mu M)\end{array}$} & \multicolumn{2}{|c|}{ No. of flowers } & \multicolumn{3}{|c|}{ Shoot length (cm) } \\
\hline & & $\begin{array}{l}\text { After } 25 \\
\text { days }\end{array}$ & $\begin{array}{c}\text { After } 45 \\
\text { days }\end{array}$ & $\begin{array}{l}\text { After } 15 \\
\text { days }\end{array}$ & $\begin{array}{l}\text { After } 30 \\
\text { days }\end{array}$ & $\begin{array}{l}\text { After } 45 \\
\text { days }\end{array}$ \\
\hline 1 & 0 & 0 & 0 & $1.6 \pm 0.6$ & $2.1 \pm 0.4$ & $2.5 \pm 0.4$ \\
\hline 2 & 10 & 0 & 1 & $2.1 \pm 0.5$ & $3.5 \pm 0.2^{*}$ & $3.7 \pm 0.5^{\star \star}$ \\
\hline 3 & 20 & 1 & 2 & $2.3 \pm 0.5$ & $3.2 \pm 0.3^{\star \star}$ & $3.9 \pm 0.5^{\star \star}$ \\
\hline 4 & 30 & 2 & 4 & $2.9 \pm 0.4$ & $4.9 \pm 0.5^{\star \star}$ & $6.4 \pm 0.4^{\star \star}$ \\
\hline 5 & 40 & 4 & 7 & $2.7 \pm 0.6$ & $3.7 \pm 0.4^{*}$ & $5.1 \pm 0.6^{\star \star}$ \\
\hline 6 & 50 & 1 & 3 & $2.6 \pm 0.5$ & $4.1 \pm 0.5^{\star \star}$ & $5.8 \pm 0.5^{\star *}$ \\
\hline
\end{tabular}

Values represent the means SE. Means followed by different asterisks are significantly different at $\mathrm{P}=0.05$ according to the least significant difference test. ${ }^{* *} \mathrm{p}<0.01 ;{ }^{*} \mathrm{p}<0.05$ (t-test).

1e) seven flowers were produced. Higher concentration of silver nitrate and cobalt chloride resulted in abnormal morphogenetic responses.

\section{Pollen transformation}

Microspore stage from the unopened flower 48 before the anthesis was used for the study and the same microspores were kept for the co-cultivation for $12 \mathrm{hrs}$. Six hrs of cocultivation showed 18\% transformation frequency (Figure 2) where as, $12 \mathrm{hrs}$ co-cultivation treatment resulted in reduced (4\%) transformation efficiency probably due to loss of viability resulting in the decreased transformation efficiency. Transient GUS expression was observed in anthers inoculated with Agrobacterium tumefaciens (Figure $3)$. No GUS expression was noticed in anthers co-cultivated for less than $4 \mathrm{hrs}$.

\section{DISCUSSION}

In the present study we had demonstrated that the influence of $\mathrm{AgNO}_{3}$ and $\mathrm{CoCl}_{2}$ on in vitro flowering of $C$. frutescens KT-OC variety. $\mathrm{AgNO}_{3}$ has been reported to inhibit ethylene action (Beyer, 1976), and cobalt ions are known to inhibit ethylene production (Lau and Yang, 1976). It was found that addition of $\mathrm{AgNO}_{3}$ to the culture media greatly improves regeneration of many dicot and monocot cultures as in case of Coffea sp., (Giridhar et al. 2003) and Vanilla planifolia (Giridhar et al. 2001) and even somatic embryogenesis in Coffea species (Giridhar et al. 2004). In the present study our results with nodal explants are in accordance with above reports. Both $\mathrm{Co}^{++}$and $\mathrm{Ag}^{++}$ enhanced the percentage of cultures forming shoots and the number of shoots produced per explant. The exact mechanism of $\mathrm{AgNO}_{3}$ mediated ethylene production and its activity regulation is unclear but it has been explained by an interference of ethylene perception or stress exerted by silver ion.

Silver nitrate is an ethylene action inhibitor and ethylene inhibits S-adenosyl methionine decarboxylase, which in turn promotes polyamine levels, which are implicated in flowering (Bais et al. 2000). Silver (silver nitrate as ethylene action inhibitor) and cobalt ions (cobalt chloride is an ethylene biosynthesis inhibitor), are also known to be involved in flower induction and other phenotypic responses (Bais et al. 2000; Obul Reddy et al. 2001). Cobalt

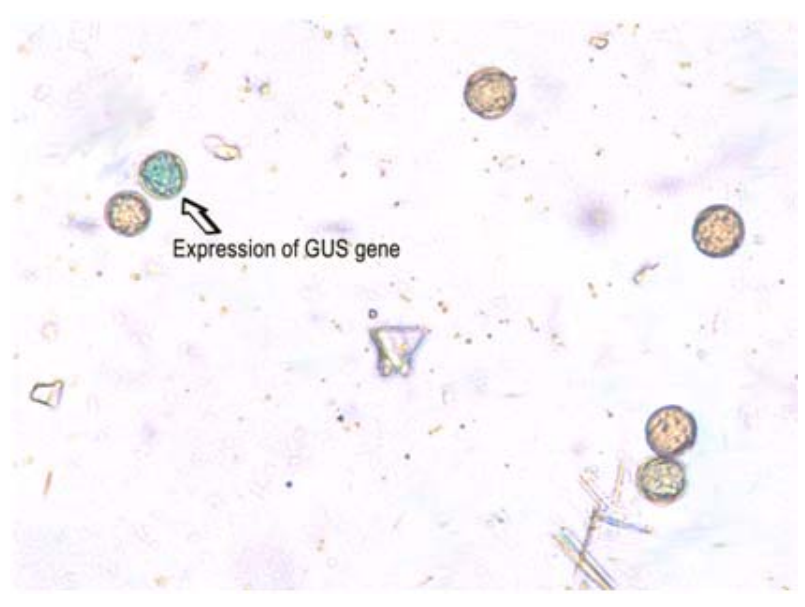

Figure 3. Expression of intron GUS gene was observed in Capsicum frutescens pollen co-cultivated with Agrobacterium tumefaciens. 
Table 2. Effect of cobalt chloride on shoot length and in-vitro flowering in C. frutescens

\begin{tabular}{|c|c|c|c|c|c|c|}
\hline \multirow{2}{*}{ S. no. } & \multirow{2}{*}{$\begin{array}{c}\text { Conc. of cobalt chloride } \\
(\mu \mathrm{M})\end{array}$} & \multicolumn{2}{|c|}{ No. of flowers } & \multicolumn{3}{|c|}{ Shoot length (cm) } \\
\cline { 3 - 7 } & 0 & $\begin{array}{c}\text { After 25 } \\
\text { days }\end{array}$ & $\begin{array}{c}\text { After 45 } \\
\text { days }\end{array}$ & $\begin{array}{c}\text { After 15 } \\
\text { days }\end{array}$ & $\begin{array}{c}\text { After 30 } \\
\text { days }\end{array}$ & $\begin{array}{c}\text { After 45 } \\
\text { days }\end{array}$ \\
\hline 1 & 0 & 0 & $1.7 \pm 0.3$ & $2.0 \pm 0.5$ & $2.4 \pm 0.4$ \\
\hline 2 & 10 & 0 & 1 & $2.4 \pm 0.2$ & $3.5 \pm 0.6$ & $4.3 \pm 0.5$ \\
\hline 3 & 20 & 2 & 3 & $2.5 \pm 0.4$ & $3.2 \pm 0.2$ & $4.1 \pm 0.2$ \\
\hline 4 & 30 & 3 & 7 & $2.9 \pm 0.2$ & $4.1 \pm 0.4^{*}$ & $5.4 \pm 0.4^{\star *}$ \\
\hline 5 & 40 & 3 & 4 & $2.5 \pm 0.5$ & $3.6 \pm 0.3$ & $4.8 \pm 0.6$ \\
\hline 6 & 50 & 2 & 3 & $2.8 \pm 0.3$ & $3.8 \pm 0.4$ & $4.6 \pm 0.2$ \\
\hline
\end{tabular}

Values represent the means SE. Means followed by different asterisks are significantly different at $\mathrm{P}=0.05$ according to the least significant difference test. ${ }^{*} \mathrm{p}<0.01 ;{ }^{*} \mathrm{p}<0.05$ (t-test).

chloride effectively inhibits ethylene production and substantially increases shoot regeneration by blocking the conversion of ACC to ethylene (Lau and Yang, 1976).

Capsicum is highly recalcitrant species and there are lots of variations with in the species for their response in tissue culture studies (Ochoa-Alejo and Ramirez-Malagon, 2001). Especially in C. annuum different cultivar varieties that are specific to geographical locations show significant variations morphologically for growth and even pungency. According to Bodhipadma and Leung (2002) the C. annuum var. sweet banana zygotic embryos were used for in vitro flowering. In fact, the said variety is non-pungent annual variety. In their subsequent report the same authors Bodhipadma and Leung (2003) used silver thiosulphate in order to achieve fruit setting in C. annuum var. sweet banana. Moreover, paper of Tisserat and Galletta (1995) mainly oriented towards obtaining in vitro flowering and fruiting from seedling tips by using Automated Plant Culture System Conditions. The selected explants are obtained from highly pungent $C$. frutescens variety, as pungency is also a factor influences response for in vitro growth. The C. frutescens (Perennial) variety which is taxonomically quite different from C. annuum (Annual) that we used for this study is an authenticated variety from DRDO Pithoragarh. For obtaining flowering we used in vitro shoots as explants and our results confirmed the requirement of $\mathrm{CoCl}_{2}$ or $\mathrm{AgNO}_{3}$ for inducing in vitro flowering. Though the ethylene biosynthesis inhibition by $\mathrm{AgNO}_{3}$ and ethylene action inhibition by $\mathrm{CoCl}_{2}$ are well documented in other plant systems (Pua et al. 1996) as mentioned above in our report we showed that their incorporation in medium may show the similar activity physiologically in $C$. frutescens and the same could be a reason for initiation in vitro flowering. Though one or other earlier reports are on C. annuum, for the first time we are claiming an in vitro flowering in an authentic high pungent Indian variety of $C$. frutescens under the influence of $\mathrm{CoCl}_{2}$ or $\mathrm{AgNO}_{3}$.

Flowering is one of the processes that may induce senescence. Hence, how ethylene inhibitors or ethylene action inhibitors can induce flowering is still a mystery. We cannot rule out the possibility that silver and cobalt ions interact with other biochemical processes required for cellular differentiation during shoot morphogenesis and floral induction in chilies. The result of this study will be useful in micro-propagation and developmental studies of floral differentiation. Hence the simple reproducible and reliable protocol for in vitro flowering has larger implication in Capsicum improvement. This is potentially useful in plant biotechnology for micro propagation, developmental biology studies and pollen transformation, which is useful in developing homozygous transgenic lines.

\section{ACKNOWLEDGMENTS}

The authors are thankful to The Defence Research Development Organization (DRDO), Pithoragarh, Uttaranchal, India for providing the germplasm and Department of Biotechnology, Government of India, for the financial assistance. A.S., V.K., are grateful to CSIR, New Delhi for the award of Research Fellowships.

\section{REFERENCES}

BAIS, Harsh Pal; SUDHA, Govinda Swamy and RAVISHANKAR, Gokare Aswathanarayan. Putrescine and 
$\mathrm{AgNO}_{3}$ influences shoot multiplication, in vitro flowering and endogenous titers of polyamines in Cichorium intybus L. cv. Lucknow Local. Journal of Plant Growth Regulation, June 2000, vol. 19, no. 2, p. 238-248.

BEYER, E.M. Silver ion: a potent anti-ethylene agent in cucumber and tomato. HortScience, 1976, vol. 11, p. 175196.

BODHIPADMA, Kitti and LEUNG, David W.M. In vitro flowering of plantlets regenerated via somatic embryogenesis from immature zygotic embryo explants of Capsicum annuum L. cv. Sweet Banana. Phyton - Annales Rei Botanicae, July 2002, vol. 42, no. 1, p. 99-108.

BODHIPADMA, Kitti and LEUNG, David W.M. In vitro fruiting and seed set of Capsicum annuum L. CV. Sweet Banana. In Vitro Cellular and Developmental BiologyPlant, September 2003, vol. 39, no. 5, p. 536-539.

BRAR, Mohanjeet S.; MOORE, Misty J.; AL KHAYRI, Jameel M.; MORELOCK, Teddy E. and ANDERSON, Edwin J. Ethylene inhibitors promote in vitro regeneration of cowpea (Vigna ungiculata L.). In Vitro Cellular and Developmental Biology-Plant, May 1999, vol. 35, no. 3, p. 222-225.

GIRIDHAR, P.; OBUL REDDY, B. and RAVISHANKAR, G.A. Silver nitrate influences in vitro shoot multiplication and root formation in Vanilla planifolia Andr. Current Science, November 2001, vol. 81, no. 9, p. 1166-1170.

GIRIDHAR, P.; INDU, E.P.; VIJAYA RAMU, D. and RAVISHANKAR, G.A. Effect of silver nitrate on in vitro shoot growth of Coffee. Tropical Science, 2003, vol. 43, no. 3, p. 144-146.

GIRIDHAR, P.; INDU, E.P.; VINOD, K.; CHANDRASHEKAR, A. and RAVISHANKAR, G.A. Direct somatic embryogenesis from Coffea arabica $\mathrm{L}$ and Coffea canephora P ex Fr. under the influence of ethylene action inhibitor-silver nitrate. Acta Physiologiae Plantarum, September 2004, vol. 26, no. 3, p. 299-305.

GURURAJ, H.B.; GIRIDHAR, P.; SHARMA, A.; PRASAD, B.C.N. and RAVISHANKAR, G.A. In vitro clonal propagation of bird eye chilli (Capsicum frutescens Mill.). Indian Journal of Experimental Biology, November 2004, vol. 42, no. 11, p. 1136-1140.

HYDE, Camille L. and PHILLIPS, Gregory C. Silver nitrate promotes shoot development and plant regeneration of chili pepper (Capsicum annuum L.) via organogenesis. In Vitro Cellular and Developmental Biology-Plant, April 1996, vol. 32, no. 2, p. 72-80.

LAU, Oi-Lim and YANG, Shang F. Inhibition of ethylene production by cobaltous ion. Plant Physiology, July 1976, vol. 58, no. 1, p. 114-117.
MURASHIGE, T. and SKOOG, F. A revised medium for rapid growth and bioassay with Tobacco tissue cultures. Physiologia Plantarum, 1962, vol. 15, p. 473-497.

OBUL REDDY, B.; GIRIDHAR, P. and RAVISHANKAR, G.A. In vitro rooting of Decalepis hamiltonii Wight \& Arn., an endangered shrub, by auxins and root promoting agents. Current Science, December 2001, vol. 81, no. 11, p. 1479-1482.

OCHOA-ALEJO, Neftali and RAMIREZ-MALAGON, Rafael. In vitro chili pepper biotechnology. In Vitro Cellular Developmental Biology-Plant, November 2001, vol. 37, no. 6, p. 701-729.

PRASAD, B.C.N.; KUMAR, V.; GURURAJ, H.B.; PARIMALAN, R.; GIRIDHAR, P. and RAVISHANKAR, G.A. Characterization of capsaicin synthase and identification of its gene (csy1) for pungency factor capsaicin in pepper (Capsicum sp.). Proceedings of the National Academy of Sciences of the United States of America, August 2006, vol. 103, no. 36, p. 13315-13320.

PUA, Eng-Chong; SIM, Guek-Eng; CHI, Gek-Lan and KONG, Lan-Feng. Synergistic effects of ethylene inhibitors and putrescine on shoot regeneration from hypocotyl explants of Chinese radish (Raphanus sativus L. var. longipinnatus Bailey) in vitro. Plant Cell Reports, May 1996, vol. 15, no. 9, p. 685-690.

RAVISHANKAR, G.A.; SURESH, B.; GIRIDHAR, P.; RAO, S.R. and JOHNSON, T.S. Biotechnological studies on capsicum for metabolite production and plant improvement. In: DE, Amit Krishna ed. Capsicum: The genus Capsicum. Harwood Academic Publishers, UK, 2003, p. 96-128.

ROUSTAN, J.P.; LATCHE, A. and FALLOT, J. Stimulation of Daucus carota somatic embryogenesis by inhibitors of ethylene biosynthesis: cobalt and nickel. Plant Cell Reports, March 1989, vol. 8, no. 3, p. 182-185.

TANG, W. High frequency plant regeneration via somatic embryogenesis and organogenesis and in-vitro flowering of regenerated plantlet in Panax ginseng. Plant Cell Reports, June 2000, vol. 19, no. 7, p. 727-732.

TISSERAT, Brent and GALLETTA, Paul D. In-vitro flowering and fruiting of Capsicum fruitescens $\mathrm{L}$. HortScience, February 1995, vol. 30, no. 1, p. 130-132.

VALERA-MONTERO, L. and OCHOA-ALEJO, N. A novel approach for Chilli Pepper (Capsicum annuum L.) plant regeneration: shoot induction in rooted hypocotyls. Plant Science, 1992, vol. 84, no. 2, p. 215-219. 